\title{
CYCLIC MECHANICAL LOAD CAUSES GLOBAL TRANSLATIONAL ARREST IN ARTICULAR CHONDROCYTES: A PROCESS WHICH IS PARTIALLY DEPENDENT UPON PKR PHOSPHORYLATION
}

\author{
Cara Lomas, Xiaodi D. Tang, Anastasios Chanalaris, Jeremy Saklatvala and Tonia L. Vincent* \\ The Kennedy Institute of Rheumatology - Cell Signalling, London, U.K.
}

\begin{abstract}
The cellular mechanisms by which articular cartilage responds to load are poorly understood, but such responses may involve regulation at the level of protein translation rather than synthesis of mRNA. We investigated the role of translational control in cyclically $(0.5 \mathrm{~Hz}, 0.1$ $\mathrm{Hz}$ and $0.05 \mathrm{~Hz}$ ) and statically loaded porcine articular cartilage explants. Messenger RNA was extracted for real time polymerase chain reaction (RT-PCR) and newly synthesised proteins were measured by their incorporation of radiolabelled ${ }^{35} \mathrm{~S}$ [methionine/cysteine] or ${ }^{35} \mathrm{SO}_{4}$. Some medium from loaded and unloaded explants was immunoblotted for type II collagen, CTGF and TIMP3. The pathways that control protein translation were investigated by immunoblotting explant lysates for PKR, PERK (PKR like endoplasmic reticulum kinase), eIF2a (eukaryotic initiation factor 2a), eEFs (eukaryotic elongation factors), and AMP-dependent kinase. Explants were also loaded in the presence of inhibitors of PKR, the fibroblast growth factor (FGF) receptor and PI3 kinase. Cyclic loading caused complete global translational arrest as evidenced by a total suppression of new protein synthesis whilst maintaining mRNA levels. Translational arrest did not occur following static loading and was partly dependent upon the load frequency. There was a rebound increase in protein synthesis when labelling was performed after load had been withdrawn. Phosphorylation of PKR occurred in explants following cyclic load and inhibition of PKR modestly reversed suppression of newly synthesised proteins suggesting that PKR, at least in part, was responsible for loading induced translational arrest. These results show that translational control provides a rapid and potentially important mechanism for controlling the synthetic responses of articular chondrocytes in response to different types of mechanical load.
\end{abstract}

Keywords: Cartilage, chondrocytes, protein synthesis, mechanical load.

\author{
*Address for correspondence: \\ Tonia L. Vincent \\ The Kennedy Institute of Rheumatology - Cell Signalling \\ 65 Aspenlea Road London, \\ London W6 8LH, U.K.
}

E-mail: t.vincent@imperial.ac.uk

\section{Introduction}

The importance of mechanical factors in controlling the functions of articular chondrocytes is undisputed. Mechanical factors contribute to the development of OA: joints that are immobilised appear protected from OA (Stecher and Karnosh, 1947; Etherington and Spector, 1995), repeated overuse of specific joints predisposes to degenerative disease (coal miners' back, foundry workers' elbow), and injury that results in destabilisation of the joint, and which presumably leads to abnormal shear in the joint is a strong risk factor for premature disease (Lohmander et al., 2007). On the other hand, physiological joint loading may protect articular cartilage; increased exercise in middle aged men leads to an increase in sulphated proteoglycan in the joint as assessed by an increase in hydration of the matrix by MRI (Buschmann et al., 1999), and patients who lose the ability to weight bear, rapidly lose cartilage volume (Vanwanseele et al., 2002). The cellular mechanotransducers that mediate cellular responses to loading are not fully characterised, but might involve integrins (Millward-Sadler et al., 1999; Lee et al., 2002), ion channels (Lee et al., 2000; Wu and Chen, 2000), intracellular calcium signalling (Roberts et al., 2001; Valhmu and Raia, 2002), TGFb (Neu et al., 2007) and pericellular FGF2 (Vincent et al., 2002; Vincent et al., 2004; Vincent et al., 2007).

Chondrocyte responses to mechanostimulation in vitro have been studied for several decades. Such experiments have been performed on cartilage explants, as well as isolated chondrocytes encapsulated within an artificial matrix. A number of cellular outcomes have been measured including synthesis of matrix proteins such as aggrecan and type II collagen, metabolic labelling of secreted and cellular proteins, catabolic activation assessed by release of glycosaminoglycan (GAG), and gene induction of candidate regulatory molecules in cartilage such as tissue inhibitors of metalloproteinase (TIMP) and matrix metalloproteinases (MMPs). Mechanical regulation of matrix synthesis in articular cartilage is perhaps the most studied, but the publications in this field are at times contradictory, suggesting that control is complex. The concept that cyclic mechanical stimulation of articular cartilage promotes synthesis of matrix proteins (Korver et al., 1992; van Kampen et al., 1994; Lee et al., 2003) and static stimulation leads to suppression of these molecules (Gray et al., 1988; Burton-Wurster et al., 1993) does not always hold true (Gray et al., 1989; Steinmeyer and Knue, 1997; Fehrenbacher et al., 2003; Ackermann and Steinmeyer, 2005). It is apparent, from close scrutiny of these papers, that control of anabolic cell processes 
is dependent upon other complex variables such as the frequency of cyclic load (Larsson et al., 1991; Kim et al., 1994; Parkkinen et al., 1992; Parkkinen et al., 1993; Valhmu et al., 1998; Buschmann et al., 1999; Sauerland et al., 2003; Sah et al., 1989), the amplitude and duration of the load (Wong et al., 1999; Bachrach et al., 1995), the nature of the force i.e. compressive versus shear (Fitzgerald et al., 2006; Neu et al., 2007) and, probably, the age and derivation of tissue in which the experiment is performed. The loading regimes range widely in the published papers and interpretation of some of these studies is also complicated by the fact that some have studied gene expression at mRNA level, whilst others the protein. One element that does emerge from many of these papers is that where regulation is seen, response rates are often very rapid leading to speculation that mechanical loading may control cellular responses at the level of protein translation or by post translational mechanisms.

Whilst investigating the control of secretion of chondrocyte proteins by mechanical loading, we chanced upon the observation that cyclic loads led to global translational arrest. Our aim was to characterise this phenomenon in more detail and to investigate the signalling pathways that might control it.

\section{Materials and Methods}

\section{Tissue and reagents}

Porcine articular cartilage explants $(6 \mathrm{~mm}$ diameter, by $2.5 \mathrm{~mm} \pm 0.2 \mathrm{~mm}$ ) were removed by punch biopsy from the femoral condyles of 6-9 month old animals and rested overnight in serum free Dulbecco's Minimal Essential Medium (DMEM) (supplemented with penicillin and streptomycin). ${ }^{35} \mathrm{~S}[$ methionine/cysteine] ([met/cys]) and ${ }^{35} \mathrm{SO}_{4}$ was obtained from Amersham, Pharmacia Biotech (Amersham, UK). Antibodies to TIMP3, PKR, eIF2a, eEF2, S6 ribosomal protein, p70 S6 kinase, eIF4E, PERK, AMP-dependent kinase including their phosphorylated forms were purchased from Cell Signalling Technology (Beverly, MA, USA). CTGF antibodies were from Santa Cruz Biotechnology (Santa Cruz, CA, USA). Secondary antibodies were from Dako (Ely, UK). Type II collagen antibody was kindly provided by Professor Vic Duance, University of Cardiff, UK. Inhibitors to PKR (527450, 1 $\mu \mathrm{M}$ ), PI3K (Ly 294002, $20 \mu \mathrm{M}$ ) were from Calbiochem/ Merck (Nottingham, UK), and FGFR (SB402451, 250nM) was synthesised following published protocols (Hamby et al., 1997). rFGF2 was purchased from Peprotech (London, UK). Human IL-1 $\beta$ was expressed in E. coli and the recombinant protein was purified in house as previously described (Bird and Saklatvala, 1990). Aliquots of IL-1 $\beta$ were stored in phosphate buffered saline (PBS) at $-20{ }^{\circ} \mathrm{C}$.

\section{Loading of cartilage explants}

Cartilage explants were placed between two polyethylene frits, then loaded (0.2 MPa) (unconfined) in serum free medium either cyclically $(0.5,0.1$ or $0.05 \mathrm{~Hz})$ or by static compression for between $15 \mathrm{~min}$ and $5 \mathrm{~h}$. Loading was performed in a pneumatically driven loading rig as
Table 1. Primers used in the present study.

\section{Aggrecan}

Forward: -5'- CCA GAA TCT AGC AGG GAG TCA TC-3'

Reverse: -5'-AGG CGA GGT GGC TTC AGT C-3'

\section{Collagen II}

Forward: -5'-CCA TCT GGC TTC CAG GGA C-3'

Reverse: -5'- CC ACG AGG CC AGG AGC T-3'

\section{GAPDH}

Forward: -5'- GAT CGA GTT GG GGC TGT GAC T-3'

Reverse: -5'- ACA TGG CCT CCA AGG AGT AAG A-3'

\section{MMP3}

Forward: 5'-CTT ACA GAC CTG GCT CGG TT-3'

Reverse: 5'-TAT ACT TGA AGG AAG AGG TG-3'

\section{TIMP1}

Forward: 5'-CTG CGG ATA CTT CCA CAG GT-3' Reverse: 5' CAA AAC TGC AGG TGG TGA TG-3'

described previously (Vincent et al., 2007) on a square waveform with slowed ramp speed to produce a sinusoidallike waveform. 0.2 $\mathrm{MPa}$ loads resulted in a maximum measured strain (by a Draper external micrometer) of 5.7 $\%$ over $4 \mathrm{~h}$. The loading rod was in contact with the tissue at the start of the experiment in order to minimise impact. Control (non-loaded) explants were placed between polyethylene frits and cultured adjacent to loaded samples.

\section{Extraction of mRNA from cartilage explants}

Explants were loaded or left unloaded for $4 \mathrm{~h}$ then snap frozen and pulverised. For RNA extraction duplicate explants were pooled. mRNA was extracted and purified from explants using Qiagen (Hilden, Germany) RNeasy Kit according to the manufacturer's instructions. $1 \mu \mathrm{g}$ of RNA was reverse transcribed into cDNA in a $20 \mu \mathrm{l}$ reaction containing $1 \mu \mathrm{l}$ of random primers (Invitrogen, Paisley, UK; 48190-011, $3 \mu \mathrm{g} / \mu \mathrm{L}$ ), $1 \mu \mathrm{L}$ of dNTP (Invitrogen 18427$088,10 \mathrm{mM}$ ), $4 \mu \mathrm{L}$ of $5 \mathrm{X}$ First-Strand buffer (Invitrogen 18064-014, SuperScript II kit), $2 \mu$ L of dithiothreitol (DTT) (Invitrogen, $0.1 \mathrm{M}$ ), $1 \mu \mathrm{L}$ of RNase inhibitor (Promega, Southampton, UK; N2615), $1 \mu \mathrm{L}$ of SuperScript II reverse transcriptase (Invitrogen 18064-014, 200 units) and $10 \mu \mathrm{L}$ of RNase-free water (Qiagen RNeasy Kit) in a thermal cycler. The resulting cDNA was then amplified using real time PCR with SYBR Green PCR Master Mix (Applied Biosystems/Life Technologies, Foster City, CA, USA) and specific forward and reverse primers (Table 1).

\section{Metabolic labelling of articular cartilage explants}

One hour prior to loading, explants were washed into methionine/cysteine-free medium. ${ }^{35} \mathrm{~S}$ [met/cys] $(50 \mu \mathrm{Ci})$ was added to fresh medium $(500 \mu \mathrm{L}) 30$ min following initiation of loading, or was added to the explant culture after loading had been completed (in fresh medium). Where explants were stimulated with IL-1 (10 ng/mL), cytokine 
was added at the time of initiation of loading. Labelling was performed for a minimum of $4 \mathrm{~h}$. Appropriate non-loaded controls were labelled in the presence of the polyethylene frits and were placed in the incubator adjacent to loaded samples. Medium was removed and explants extracted using a dissociative lysis buffer. Proteins were run on NuPage 4-12 \% Tris/Gly gradient gels (Invitrogen) under reduced conditions, dried and silver stained. Newly synthesised proteins were visualised by autoradiography. Some explants were stimulated with rFGF2 $(50 \mathrm{ng} / \mathrm{mL})$ prior to labelling. Where the effect of an inhibitor was being assessed, the explant was pre-incubated with the inhibitor for at least $12 \mathrm{~h}$ prior to loading (to ensure full equilibration). Fresh inhibitor was added with each change of medium.

For ${ }^{35} \mathrm{SO}_{4}$ incorporation, explants were loaded as above, but incubated with $25 \mu \mathrm{Ci} / \mathrm{mL}^{35} \mathrm{SO}_{4}$ Explants and media were separately digested $\left(2 \mathrm{~h}, 65^{\circ} \mathrm{C}\right)$ in $0.25 \mathrm{~mL}$ of $25 \mu \mathrm{g} / \mathrm{mL}$ papain in $0.05 \mathrm{M}$ sodium phosphate, $1 \mathrm{mM}$ EDTA, 2 mM N-acetylcysteine. Glycosaminoglycans were precipitated with $10 \%$ cetyl pyridinium chloride (CPC) and washed three times with $3 \% \mathrm{CPC}$. The pellets were dissolved in formic acid, mixed with $3 \mathrm{~mL}$ scintillant and counted in a liquid scintillation counter.

\section{Immunoblotting for secreted proteins}

To verify the suppression of protein synthesis with cyclic loading, samples of explant media from loaded and non-loaded explants were immunoblotted for known constitutively secreted chondrocyte proteins (type II collagen, connective tissue growth factor (CTGF) and tissue inhibitor of metalloproteinase 3, (TIMP3)). Explants were loaded as before and medium collected for $4 \mathrm{~h}$ either during the loading cycle or following cessation of loading. Medium collection was commenced $30 \mathrm{~min}$ after loading in order to allow protein that was already translated and destined for cellular secretion to be exported and discarded. Medium was concentrated by acetone precipitation ( $400 \mu \mathrm{L}$ of acetone per $100 \mu \mathrm{L}$ of medium), dried, then solubilised with sodium dodecyl sulphate (SDS) sample buffer. Proteins were resolved by $8 \%$ SDSpolyacrylamide gel electrophoresis (PAGE), transferred onto polyvinylidenefluoride (PVDF), then immunoblotted with anti collagen, anti CTGF or anti TIMP3 antibodies (all at 1:1000). Bands were visualised by enhanced chemiluminescence (ECL). For protein quantification, autoradiographs were scanned at a resolution of 600 dpi and protein bands were quantified by Quantity One software from Bio-Rad (Hemel Hempstead, UK). A paired $t$-test was performed to detect significant differences in the PKR inhibitor-treated samples, as well as the degree of translational arrest with changes in loading frequency.

\section{Immunoblotting for intracellular signalling proteins}

Four explants were loaded for each time point, ranging from 2 min to $4 \mathrm{~h}$. Explants were lysed in a dissociative buffer containing protease, and phosphatase inhibitors. Lysates were mixed with sample buffer, containing DTT (10 $\mathrm{mmol})$, concentrated by acetone precipitation as above, and run on $12 \%$ SDS-PAGE. Immunoblotting was performed as for type II collagen (above).

\section{Results}

\section{Cyclic loading of articular cartilage explants results} in global suppression of protein synthesis

The response of articular chondrocytes to cyclic loading was investigated through metabolic labelling whereby newly synthesised proteins are visualised by autoradiography through their incorporation of ${ }^{35} \mathrm{~S}$ [met/cys]. Articular cartilage explants were cyclically loaded (L) (0.2 MPa, $0.5 \mathrm{~Hz}$ ) or non-loaded (C) and newly synthesised proteins assessed by the incorporation of ${ }^{35} \mathrm{~S}[\mathrm{met} / \mathrm{cys}]$ into cellular and secreted proteins. (Fig. 1A). Several secreted proteins were seen in the non-loaded explants which have been identified previously (Vincent et al., 2002). These included prominent bands at $150-190 \mathrm{kDa}$, which include type II collagen, a strong band at around $39 \mathrm{kDa}$ (osteonectin, also known as SPARC), and a strong band below this which is the C-pro peptide of type II collagen. Loaded patterns were characterised by complete absence of secreted and cellular (Fig. 1A, Loaded) newly synthesised protein. Owing to the unexpected nature of this result, the experiment was repeated several times. In total we performed 12 labelling experiments, each one with experimental replicates (i.e., 2 loaded and 2 unloaded samples). Complete suppression of new protein synthesis was seen in 11 out of 12 experiments. A partial response was seen in one experiment.

IL-1 is a known strong catabolic stimulus and induces a number of newly synthesised proteins that can be detected by metabolic labelling including MMPs, TIMP1, gp38 and serum amyloid A(Vincent et al., 2002). Cartilage explants were stimulated with IL-1 in the presence or absence of cyclic loading to see whether strong cytokine stimulation was able to overcome the cellular arrest of protein translation. IL-1 changed the pattern of secreted proteins consistent with what we have published previously. This pattern was completely suppressed when stimulation was performed at the same time as cyclic loading (Fig. 1B).

We also performed a similar experiment where we labelled loaded cartilage explants with ${ }^{35}\left[\mathrm{SO}_{4}\right]$ to detect newly synthesised proteoglycan. In accordance with the complete suppression of all newly synthesised proteins, we found that loading strongly suppressed incorporation of $\mathrm{SO}_{4}$ into matrix proteins (Fig. 1C), representative of 3 similar experiments). IL-1, which characteristically partially suppresses proteoglycan synthesis, is shown as a control (Fig. 1C, IL-1).

One possibility was that cyclic loading was preventing the diffusion of radiolabel into the explant. We checked that cyclic loading did not interfere negatively with diffusion into the explant by examining the diffusion of Safranin $\mathrm{O}$ in loaded or non-loaded explants. Far from preventing diffusion through the explant, loading positively increased the diffusion of Safranin O in loaded compared to nonloaded explants (data not shown).

To support further our observation, we also immunoblotted a selection of known constitutively secreted chondrocyte proteins: CTGF, TIMP3 and type II collagen. Cyclic load caused complete suppression of CTGF protein secretion during a $4 \mathrm{~h}$ cyclic load compared to non-loaded explants (Fig. 1D, CTGF). This experiment was representative of a total of 5 separate experiments. Two 
(A)
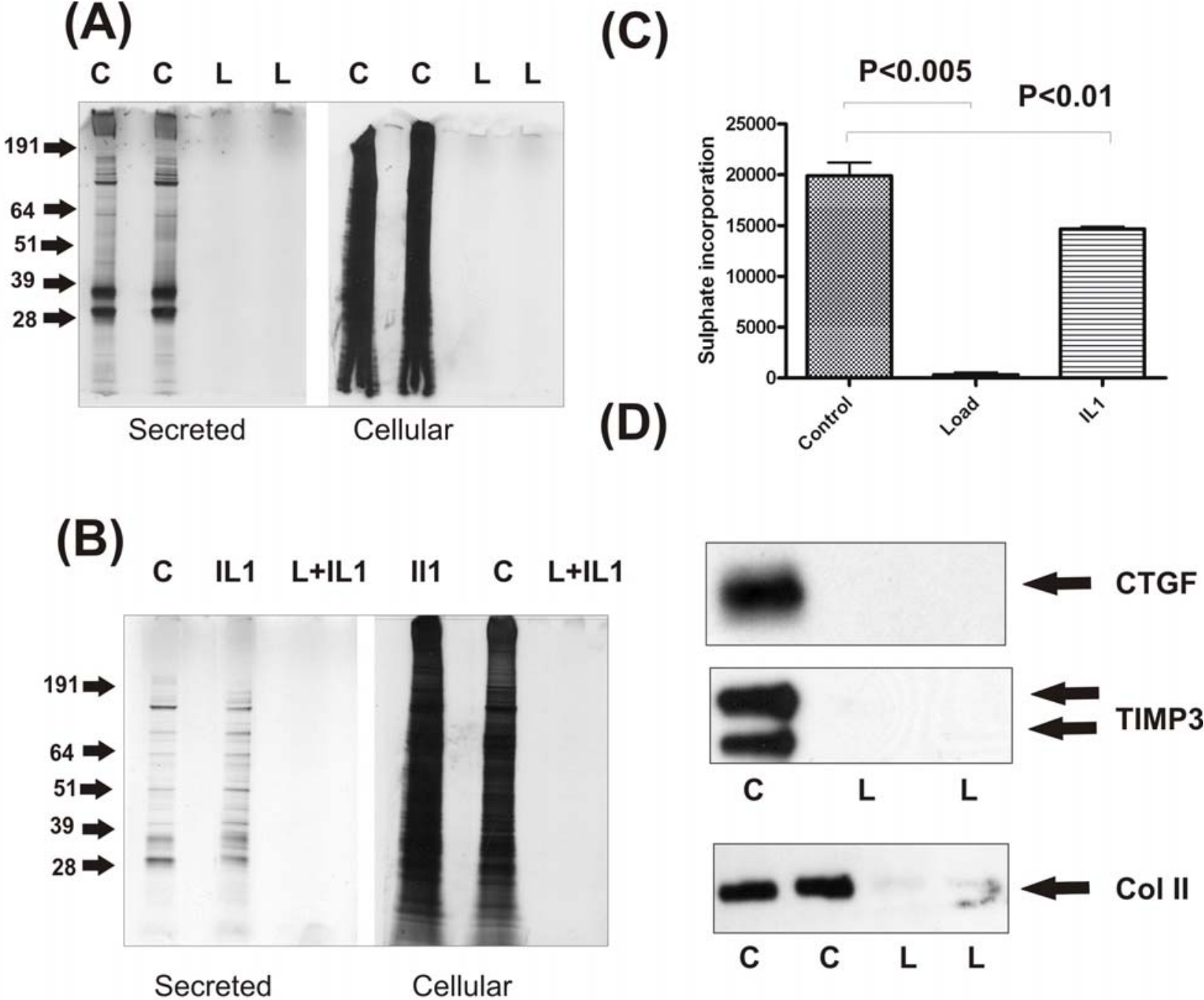

Fig. 1. Cyclic mechanical load of articular cartilage causes global suppression of protein synthesis. Articular cartilage explants were rested in serum free medium overnight then washed into methionine/cysteine free medium for $1 \mathrm{~h}$. Explants were either loaded cyclically $(0.5 \mathrm{~Hz}, \mathrm{~L})$, or left unloaded (c) for $30 \mathrm{~min}$. Medium was exchanged and ${ }^{35} \mathrm{~S}[\mathrm{met} / \mathrm{cys}]$ was added. Loading continued for $4 \mathrm{~h}$ after which the medium was removed and explants lysed. Media and lysates were resolved by SDS-PAGE, gels dried and newly synthesised proteins visualised by autoradiography (A). Some explants were loaded and labelled as above whilst stimulated simultaneously with IL1 (10 ng/mL) (L+IL1) (B). Some explants were loaded as above but in the presence of ${ }^{35} \mathrm{SO}_{4}$ to measure newly synthesised proteoglycan. IL-1 is shown as a control (C). $n=3$, statistical significance by non-paired $t$-test is shown. Media from loaded and unloaded explants $(4 \mathrm{~h})$ were immunoblotted for selected proteins, CTGF, TIMP3 and Collagen II (D).

of the western blots from the aforementioned experiments were stripped and re-probed for TIMP3 (Fig. 1D, TIMP3). Type II collagen was also detected in the medium of nonloaded explants, and was completely suppressed when explants were loaded. This result is representative of a further 4 experiments.

\section{Cyclic load does not suppress gene transcription}

We next examined whether suppression of protein synthesis upon loading was due to suppression of transcription. mRNA was extracted from explants which had been either rested or cyclically loaded for $4 \mathrm{~h}$ as above. RT-PCR was performed for a number of chondrocyte genes including type II collagen, aggrecan, MMP3, tissue inhibitor of metalloproteinase (TIMP)-1, and the house keeping gene GAPDH (Fig. 2). Whilst modest changes in the fold change were seen, these did not reach statistical significance, and the suppression of protein synthesis could not be accounted for by suppression of gene transcription. This indicated that suppression of protein production was most likely due to translational arrest.

\section{A rebound increase in protein synthesis is seen in loaded explants when load is withdrawn}

To exclude the possibility that loading had caused irreversible chondrocyte injury, some explants were loaded for $4.5 \mathrm{~h}$ as above, rested overnight, then labelled the following day for $4 \mathrm{~h}$ with ${ }^{35} \mathrm{~S}$ [met/cys] as before. Fig. $3 \mathrm{~A}$ shows that when labelling was performed following (as opposed to during) loading, there was a rebound increase in protein synthesis in both the cellular and secreted fractions (Fig. 3A, OL). Global protein synthesis 
TIMP1
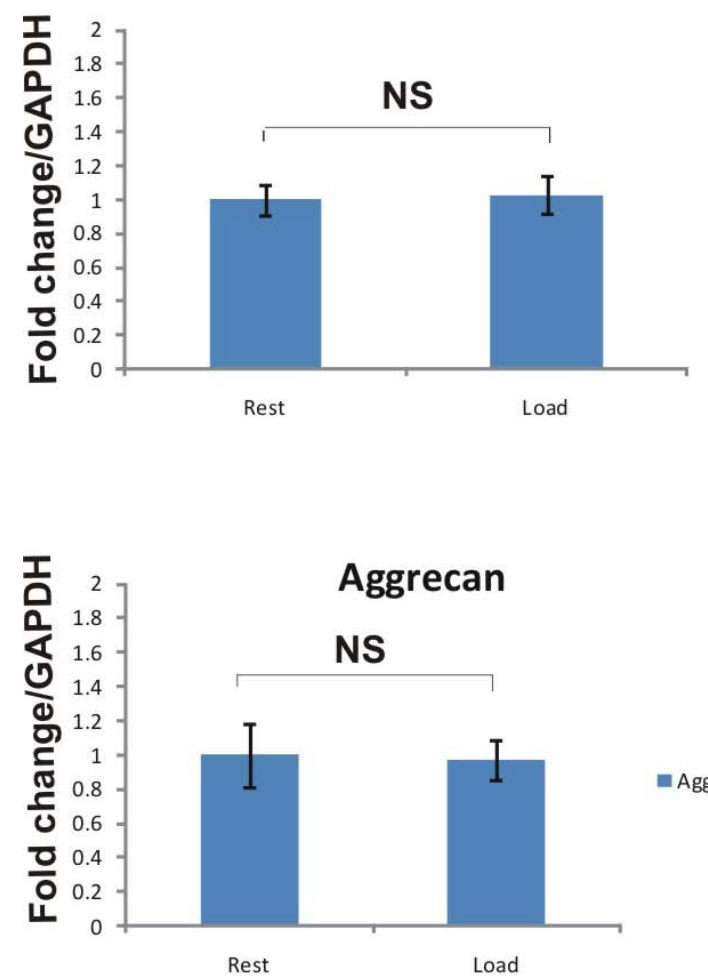

MMP3
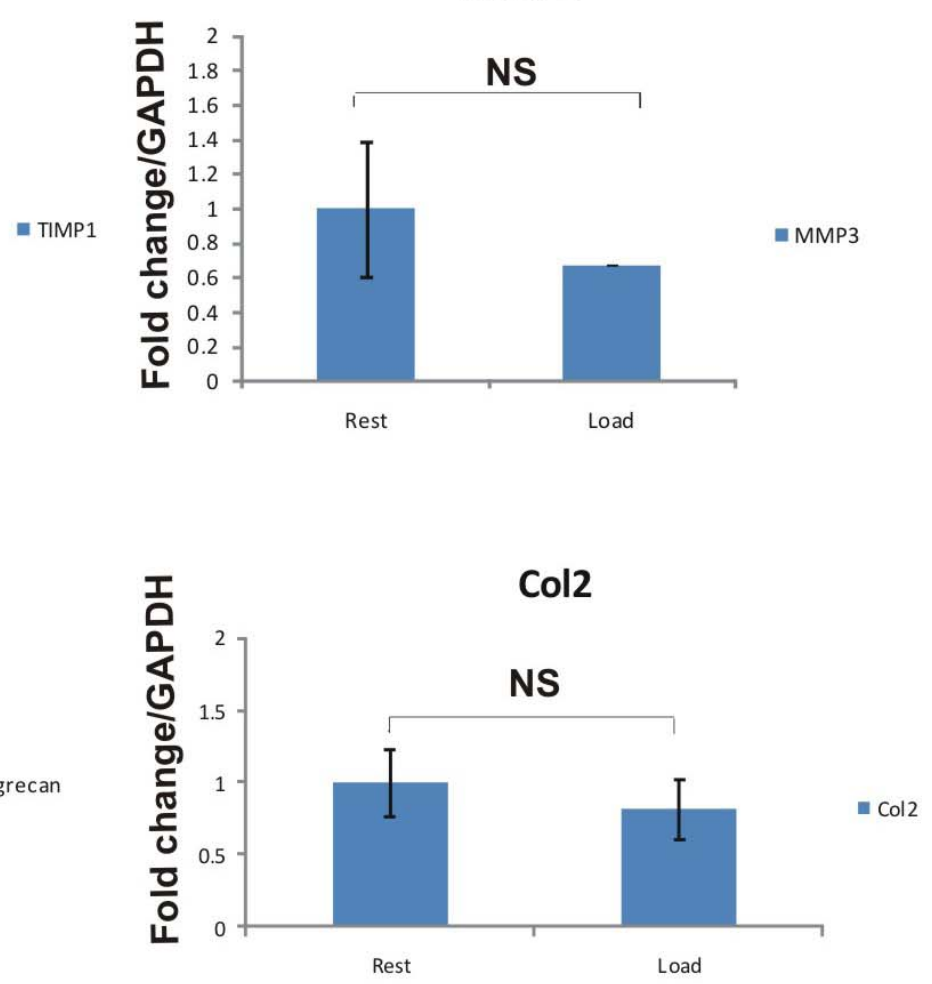

Fig. 2. mRNA levels of selected matrix genes following cyclic loading of cartilage explants. mRNA was extracted from loaded and non-loaded explants ( 2 explants per analysis) and RT-PCR performed. Data for 4 chondrocyte genes are shown and expressed as the fold change relative to GAPDH. $n=4$, NS= non-significant by non-paired $t$-test .

recovered and there was selective super-induction of some of the secreted proteins. Those bands which were stronger in the off-loading pattern (OL) included those below 191 $\mathrm{kDa}$ (this region contains type II collagen, fibronectin and some complement components (Hermansson et al., 2004)), MMPs (in the region of the $51 \mathrm{kDa}$ marker) and TIMP1 (the smear below the prominent C-propeptide band of type II collagen at $28 \mathrm{kDa}$ ). This is consistent with our previous observation (Vincent et al., 2004). In order to determine how quickly the chondrocytes recovered after a period of loading, a series of similar experiments were performed where the interval following loading was shortened. In these experiments, rather than performing metabolic labelling, we studied the secretion of type II collagen into the medium by western blot. Cartilage explants were loaded for either 15,30 or $60 \mathrm{~min}$ then medium was collected during the last $2 \mathrm{~h}$ of a $2 \mathrm{~h}, 4 \mathrm{~h}, 6$ $\mathrm{h}$ or overnight $(\mathrm{O} / \mathrm{N})$ rest period. Medium samples were immunoblotted for type II collagen. This demonstrated that an overnight recovery period (approximately $15 \mathrm{~h}$ ) was necessary to see resumption of protein synthesis and that this was irrespective of how long the cartilage was loaded for (15, 30 or $60 \mathrm{~min}$ ) (Fig. 3B). There did not appear to be a super-induction of type II collagen in the off-loading period by Western blot.

Cyclic but not static loads cause translational arrest and is frequency dependent

We next investigated whether translational arrest was induced by static as well as cyclic loads at varying frequencies. Such experiments revealed that high frequency cyclic loads $(0.5 \mathrm{~Hz}, 1: 1)$ were the most potent at suppressing protein synthesis, whilst static compression (SL) showed no suppression at all, and resembled the rested explants (Fig.4A). In the case of cyclic loads at 0.1 (1:9) $\mathrm{Hz}$, an intermediate response was observed (Fig. 4B). The combined results of 6 experiments were quantified and are shown in Fig. 4C. These results demonstrate that loading at $0.1 \mathrm{~Hz}$ was consistently less effective at suppressing protein secretion compared to loads at $0.5 \mathrm{~Hz}$. Even though translational arrest was to some extent frequency of load dependent, the load frequency did not appear to have a linear relationship with the degree of translational arrest (loading at $0.05 \mathrm{~Hz}$ looked similar to $0.1 \mathrm{~Hz}$, Fig. 4B). The fact that translational arrest was not stimulated by static loading perhaps suggests that the cell is responding to the 'release' phase of the individual load cycle rather than the 'compression' phase.

\section{Translational arrest is not mediated by FGF2 activation but is partially PKR dependent}

Previously, we have demonstrated that there is an FGFdependent activation of the extracellularly regulated kinase (ERK) upon cyclic loading of articular chondrocytes (Vincent et al., 2004). We asked whether mechanical arrest was mediated through FGF receptor tyrosine kinase activation. Cartilage explants were rested overnight in the FGFR inhibitor, SB4024541 (250 nM), which blocks FGF signalling by binding to the intracellular ATP binding site of the receptor. Explants were either loaded or rested in the 


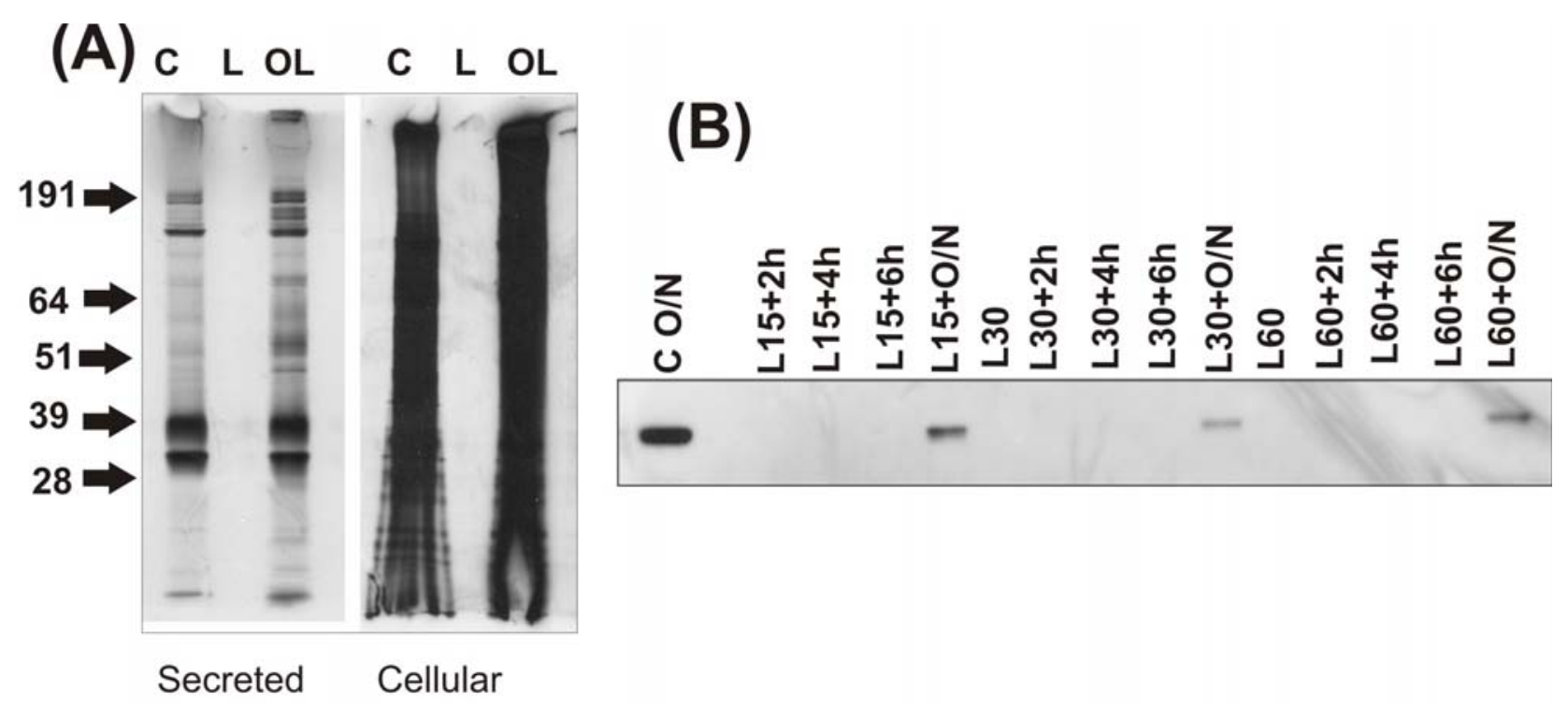

Fig. 3. Overnight off-loading results in rebound protein synthesis. Cartilage explants were loaded as before, but after $4 \mathrm{~h}$ of loading explants were rested for approximately $15 \mathrm{~h}$ i.e. off-loaded (OL). The explants were then exchanged into met/cys free medium and labelled with ${ }^{35} \mathrm{~S}[\mathrm{met} / \mathrm{cys}]$ for $4 \mathrm{~h}$. Cellular and secreted proteins were resolved and visualised as before (A). To assess the duration of rest required to initiate a recovery in protein synthesis, cartilage explants were loaded for 15,30 or $60 \mathrm{~min}(\mathrm{~L} 15,30,60)$ then rested for varying periods from $2 \mathrm{~h}$ to overnight $(15 \mathrm{~h})$. Medium was collected from the last $2 \mathrm{~h}$ of each period and run on 4-12\% SDS-PAGE. Gels were transferred and western blotted with an anti-type II collagen antibody (1:1000) (B).

(A)

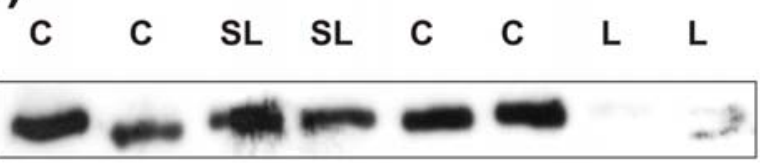

(B)

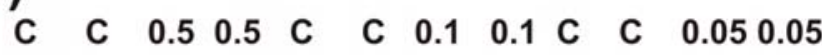

(C)

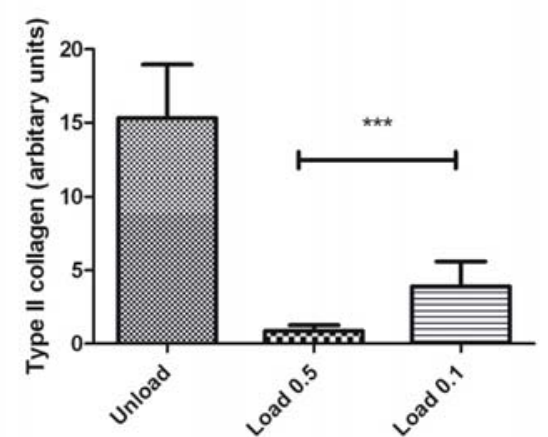

Fig. 4. Translational arrest is frequency of load dependent. Cartilage explants were either rested (c), statically loaded (SL) or cyclically loaded, $0.5 \mathrm{~Hz}$ (L) for $4.5 \mathrm{~h}$. Medium collected for the last $4 \mathrm{~h}$ of loading and was western blotted for type II collagen as above (Fig. 3B) (A). A similar experiment was performed, but cyclical loading was varied so as to produce either $0.5 \mathrm{~Hz}, 0.1 \mathrm{~Hz}$ or $0.05 \mathrm{~Hz}$ cyclic loading over $4.5 \mathrm{~h}$ (B). Protein bands from 6 experiments were quantified and are shown in (C). Differences between $0.5 \mathrm{~Hz}$ loading and $0.1 \mathrm{~Hz}$ loading compared to non-loaded explants are shown. Significance is by non paired $t$-test.

presence or absence of the inhibitor (FGFRi). Inhibition of FGF signalling had no effect on the translational arrest following cyclic loading (Figure 5(A)). SB402451 was shown to be effective in this explant system as it was able to inhibit ERK activation upon loading and rFGF2 stimulation (data not shown).

Protein translation requires three principal steps involving a number of eukaryotic initiation (eIF) and elongation (eEF) factors (reviewed in (Proud, 2007)). The initial step involves recruitment of Met-tRNAi (initiator) to the $40 \mathrm{~S}$ ribosome. This step involves eIF2a and is followed by an eIF4E-dependent recruitment of the ribosome to the mRNA. Finally the strand is elongated, a process which requires various eEFs. These eukaryotic factors are phosphorylated by cellular kinases which either promote cellular translation (phosphorylated eIF4E) or suppress it (phosphorylated eIF2a and eEFs). Well described protranslation pathways include one involving the mammalian target of Rapamycin (mTOR) pathway which is activated by PI3kinase and leads to phosphorylation of p70 S6 kinase and its substrate the S6 ribosomal protein. There are a number of pathways that result in global translational arrest. Of these, the best described include PKR and AMP-dependent kinase (for reviews see Williams, 2001 and Hardie, 2007). We studied whether translational arrest could be inhibited by a well validated inhibitor of PKR 
(A)

(C)
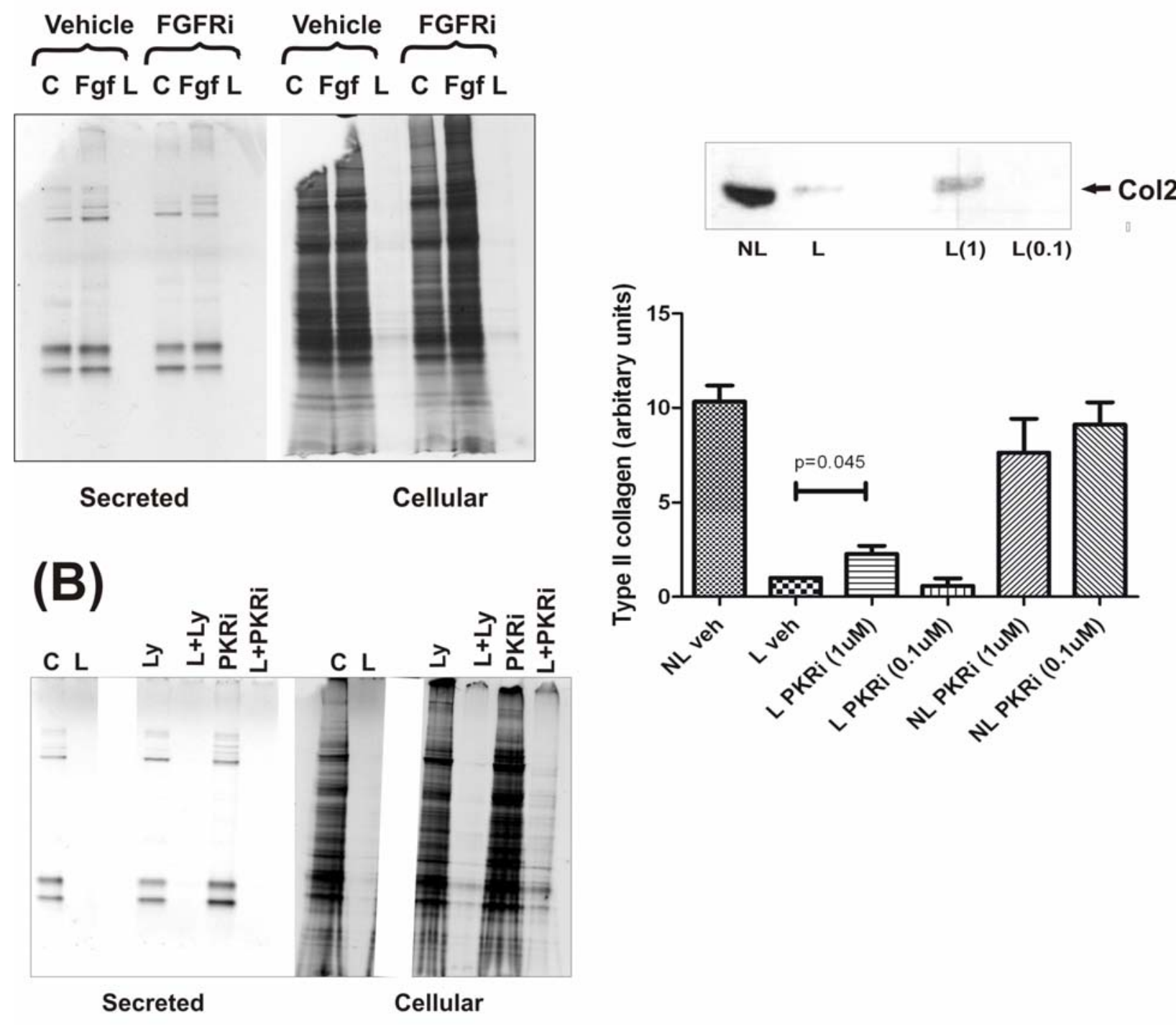

Fig. 5. Loading-induced translational arrest is partially dependent upon PKR, but not PI3 kinase or FGFR activation. Explants were pre-incubated with the FGFR inhibitor, SB402451 (100 nM), or vehicle (0.1\% DMSO), then either stimulated with rFGF2 $(50 \mathrm{ng} / \mathrm{mL})$ or were cyclically loaded $(0.5 \mathrm{~Hz})$ as above (L). Metabolic labelling was performed as above and secreted and cellular proteins viewed by autoradiography (A). Also, explants were pre-incubated with either the PI3 kinase inhibitor, Ly $(1 \mu \mathrm{M})$, or with the PKRi $(1 \mu \mathrm{M})$ then loaded and labelled as above (B). Additionally, 3 further experiments were also performed in the presence of the PKR inhibitor ( 1 or 0.1 $\mu \mathrm{M}$ ) or vehicle (veh), but media were western blotted for type II collagen. The bands were quantified and statistical significance determined by a non paired $t$-test (C). A representative western blot is also shown. NL - non-loaded, $\mathrm{L}$ - loaded.

(Jammi et al., 2003), and also tested whether the PI3K inhibitor Ly294002, was able to induce translational arrest in chondrocytes. Explants were pre-incubated with the relevant inhibitor and metabolically labelled as before. No change in the pattern of newly synthesised protein was apparent in the rested or loaded explants in the presence of the Ly inhibitor suggesting that blocking this pathway in isolation was insufficient to induce translational arrest in chondrocytes. When explants were pre-incubated with the PKR inhibitor (at a dose which inhibited DTT-induced PKR phosphorylation (not shown)), there was a subtle increase in the pattern of newly synthesised proteins, seen in the cellular, but not secreted, fractions (Fig. 5B, L+PKRi, cellular). To verify whether this was a real effect, 3 separate experiments were performed in which type II collagen was immunoblotted from the medium of loaded, or non-loaded, explants in the presence of the PKR inhibitor or its vehicle control (DMSO $0.001 \%$ ). Fig. $5 \mathrm{C}$ shows a representative western blot, and the quantified bands from the three experiments. They confirm a subtle increase in collagen secretion when loading was performed in the presence of the PKR inhibitor $(1 \mu \mathrm{M})$. No response was seen at $0.1 \mu \mathrm{M}$, 
(A)

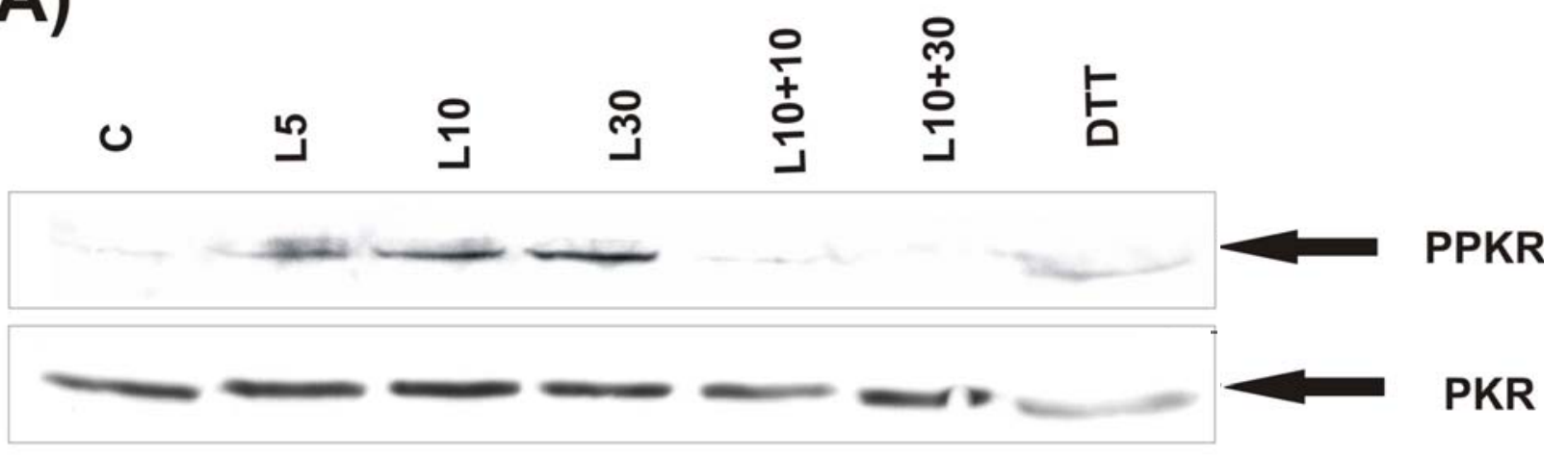

\section{(B) $\quad$ C4 $\quad$ L4 $\quad$ DTT4}

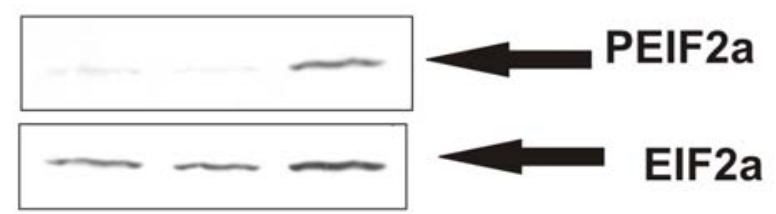

Fig. 6. Loading induces phosphorylation of PKR. Explants (in triplicate) were cyclically loaded for each time point $(5,10$ and $30 \mathrm{~min})$, were left unloaded (C), or were loaded for $10 \mathrm{~min}$ then off-loaded for either 10 (L10+10) or $30 \mathrm{~min}(\mathrm{~L} 10+30)$. Explants were lysed, triplicates pooled and lysates concentrated by acetone precipitation. Lysates were western blotted for phopho PKR (PPKR) and reprobed for total PKR (PKR) (A). A similar experiment was performed for phosphorylation of eIF2a in which explants were rested (C4) or cyclically loaded (L4) for $4 \mathrm{~h}$. The reducing agent DTT (4h stimulation) was used as a positive control for both experiments (DTT and DTT4) (B).

nor at $10 \mu \mathrm{M}$, although the latter was deemed to be toxic as the explants failed to recover protein synthesis once the load had been withdrawn (data not shown).

\section{Loading induces phosphorylation of PKR but not eIF2a}

We next tested whether PKR was phosphorylated in loaded explants. For these experiments, 3 explants were pooled and the lysates concentrated by acetone precipitation. Fig. 6A demonstrates phosphorylation of PKR at 5, 10 and $30 \mathrm{~min}$ following initiation of loading. Interestingly, if explants were loaded for $10 \mathrm{~min}$ then rested for either 10 or $30 \mathrm{~min}(\mathrm{~L} 10+10, \mathrm{~L} 10+30)$, phosphorylation of PKR was completely inhibited, suggesting that PKR is highly sensitive to cyclic loading. eIF2a, which is a key initiating factor in protein translation and which is directly phosphorylated by PKR was next tested. Surprisingly, we were unable to demonstrate phosphorylation of eIF2a either at early time points (data not shown), or after $4 \mathrm{~h}$ of loading (Fig. 5B). Stimulation of the explants with DTT, a reducing agent that induces translational arrest by stimulating the 'unfolded protein response' caused phosphorylation of both PKR and eIF2a. As translational arrest was only partially affected by PKR inhibition, the results suggested that PKR was not the principal pathway responsible for translational arrest upon cyclic loading. We also looked for phosphorylation of components of other pathways known to influence protein translation including S6kinase, PERK (PKR-like ER kinase) and AMP-dependent kinase, as well as the phosphorylation of other eukaryotic factors including eEIF4E, and eEF2. We were unable to demonstrate consistent activation of any of these other molecules in response to loading cartilage explants (data not shown).

\section{Discussion}

Our results suggest that there is a highly robust frequencydependent arrest of protein translation when articular cartilage is cyclically loaded. This causes complete cessation of newly synthesised secreted and cellular proteins within 15 min of loading whilst not substantially affecting mRNA levels. A $15 \mathrm{~h}$ rest period following loading allows the cells to resume protein translation leading to recovery of global synthesis with rebound of selective proteins. Our results also showed that loading-induced translational arrest was able to overcome IL1 stimulation of articular chondrocytes as seen by complete inhibition of the metabolic labelling patterns when cartilage explants were loaded and stimulated with IL-1 simultaneously. Others have demonstrated the suppression of IL-1induced production of nitric oxide and prostaglandin E2 when agarose encapsulated chondrocytes were cyclically loaded (Chowdhury et al., 2008), and it is conceivable that translational arrest could account for these changes.

The pervading view is that cyclic, but not static, loading is anabolic and causes an increase in synthesis of matrix proteins. So how do our findings fit with those already published? Two possible explanations emerge on review 
of the published literature. The first is that a number of publications have looked only at mRNA levels and made assumptions about the 'anabolic' nature of the stimulus accordingly. Data regarding the protein response in these studies is missing (Jin et al., 2000; Smith et al., 2000; Fehrenbacher et al., 2003; Ikenoue et al., 2003; Fitzgerald et al., 2006). Secondly, in some publications protein levels have been measured but this has been done after loading. In other words, these measurements could represent the 'rebound' phase of protein synthesis that we describe after load withdrawal (Palmoski and Brandt, 1984; De Croos et al., 2006). Indeed, we ourselves previously published that cyclic loading causes an FGF-dependent increase in TIMP1 protein in articular cartilage explants. These had been metabolically labelled $\left({ }^{35} \mathrm{~S}[\mathrm{met} / \mathrm{cys}]\right)$ during a $5 \mathrm{~h}$ period following the cessation of load (Vincent et al., 2004). In some studies, metabolic labelling was performed both during and after load withdrawal. These studies invariably show an increase in matrix production during the withdrawal phase (Sah et al., 1989; Kim et al., 1994; Burton-Wurster et al., 1993; Neu et al., 2007). Finally, there remain a number of publications in which protein and proteoglycan synthesis is detected/regulated when measurements are made during cyclic or static loading (Palmoski and Brandt, 1984; Gray et al., 1988; Gray et al. 1989; Sah et al., 1989; Larsson et al., 1991; Kim et al., 1994; Steinmeyer and Knue, 1997; Wong et al., 1999; Sauerland et al., 2003). In these cases, it is not possible to rationalise why our data are at odds. Not only are the methodologies for detecting protein and proteoglycan synthesis different from the ones we employed (in older publications GAG release, or total explant incorporation of radiolabel, relatively crude measures, were used), but the loading protocols are highly varied making comparisons very difficult. Factors such as age of tissue, species, presence of serum in medium, absolute tissue strain and strain rate, may also contribute to these apparent inconsistencies. The absence of serum in our experiments is worthy of further discussion. Serum starvation is well known to induce translational arrest in eukaryotic cells by a PKR/EIF2 $\alpha$. dependent mechanism (Montine and Henshaw, 1989; Patel et al., 2000; Daher et al., 2009), presumably representing an evolutionarily conserved pathway whereby a cell is able to turn off energy expensive cellular activity (protein translation) when food is scarce. Although our experiments were performed in serum-free medium it seems unlikely that this contributed to the translational arrest upon loading. Firstly, the control (and statically-loaded) explants were also in serum free medium and secreted protein 'normally', and secondly, there was a rebound increase in protein synthesis seen in the explants that had been loaded, despite being maintained in serumfree medium for the full duration of the experiment. The only shared conclusion, from the aforementioned studies as well as ours, is that the data point towards an important role for load frequency in determining the cellular outcome.

The enormous variability in cellular responses to loading in vitro does raise the question of whether in vitro loading of cartilage explants is physiological, and/ or informative. It is certainly the case that removal of cartilage from its radial attachments within the joint as well its basal attachments to subchondral bone will alter the biomechanical properties of the tissue. Application of 'physiological' loads will necessarily therefore lead to non-physiological strain within the explant. The huge variability in load frequencies that have been used in different studies further indicates the problems researchers have in deciding what constitutes physiological load. There are other considerations also. We have previously shown that removal of cartilage explants from the joint produces a strong cellular response in chondrocytes and results in the activation of inflammatory mitogen activated protein kinase pathways as well as causing the release of the growth factor FGF2 (Vincent et al., 2002; Gruber et al., 2004). Although we 'rested' our explants for $24 \mathrm{~h}$ prior to loading, it may nonetheless mean that explants used for loading studies are quite different in their responses compared to intact, non-injured cartilage. This may also explain why the non-loaded cartilage in this and other studies is apparently highly synthetic. Even if we accept these concerns, a number of in vitro outcome measures have been verified in vivo in response to loading (such as the increase in GAG synthesis), and importantly, in vitro loading studies have confirmed the highly mechanosensitive nature of the chondrocyte. Readouts of mechanosensitive responses provide a useful tool for studying up stream mechanisms of mechanosensing in cartilage and are likely to inform physiological responses in vivo.

Control of translation is an essential and highly conserved response, which allows cells to respond rapidly to changes in their environment either to shut down synthesis (amino acid deprivation, viral infection and cell stress) or to increase growth when the environment is favourable. PKR was first described as a kinase activated by double stranded RNA, thus potentially representing a novel innate pathway leading to suppression of viral replication by inhibiting viral protein translation (Nanduri et al., 2000; Garcia et al., 2006; Sen and Peters, 2007). PKR phosphorylates eIF2a directly leading to suppression of translation initiation (Colthurst et al., 1987). It also induces the phosphatase PP2A which prevents phosphorylation of eIF4E thus inhibiting binding of the ribosome to 5'cap mRNAs (Xu and Williams, 2000). AMP-dependent kinase is activated by a reduction in the ratio of AMP:ATP; in other words, when cellular energy stores are low. This has the effect of rapidly turning off high energy requiring activities (tRNA elongation) to preserve energy supplies. At least two established mechanisms have been described for translational arrest by AMP-dependent kinase; these include the phosphorylation of eEF kinase which phosphorylates eEFs and results in a reduction of elongation, and another which leads to the suppression of the mTOR complex (reviewed in (Hardie, 2007)). It is not entirely clear what the mechanism of translational arrest is in loaded articular cartilage explants. We demonstrated a consistent, but modest increase in phosphorylation of PKR but were unable to show phosphorylation of eIF2a or changes in the phosphorylation status of eIF4E. When we inhibited PKR a modest reversal of translational arrest was apparent in the pattern of labelled cellular proteins and the secretion of type II collagen consistent with partial involvement of this pathway. This pathway has been shown 
to be active in chondrocytes although not specifically by cyclic loading (Gilbert et al., 2002; Tam et al., 2007). We investigated a number of additional translation pathways including the p70 S6 kinase, AMP-dependent kinase and PERK (a kinase involved in translational regulation following endoplasmic reticulum stress). None of these was consistently regulated although we recognise that such experiments inevitably capture only a 'snapshot' of the cellular response, and transient activation of any of these pathways may have been missed. The recent identification of a novel eIF2a-independent pathway of translational arrest indicates that there are likely to be other, as yet unidentified, pathways that might be involved (Wang and Proud, 2008). Whatever the mechanism, it is the case that control of protein synthesis at the level of translation could provide a rapid and energy efficient way of modulating chondrocyte responses to changes in the mechanical environment of the joint.

\section{References}

Ackermann B, Steinmeyer J (2005) Collagen biosynthesis of mechanically loaded articular cartilage explants. Osteoarthritis Cartilage 13: 906-914.

Bachrach NM, Valhmu WB, Stazzone E, Ratcliffe A, Lai WM, Mow VC (1995) Changes in proteoglycan synthesis of chondrocytes in articular cartilage are associated with the time-dependent changes in their mechanical environment. J Biomech 28: 1561-1569.

Bird T, Saklatvala J (1990) Down-modulation of epidermal growth factor receptor affinity in fibroblasts treated with interleukin 1 or tumour necrosis factor is associated with phosphorylation at a site other than threonine 654. J Biol Chem 265: 235-240.

Burton-Wurster N, Vernier-Singer M, Farquhar T, Lust G (1993) Effect of compressive loading and unloading on the synthesis of total protein, proteoglycan, and fibronectin by canine cartilage explants. J Orthop Res 11: 717-729.

Buschmann MD, Kim YJ, Wong M, Frank E, Hunziker EB, Grodzinsky AJ (1999) Stimulation of aggrecan synthesis in cartilage explants by cyclic loading is localized to regions of high interstitial fluid flow. Arch Biochem Biophys 366: 1-7.

Chowdhury TT, Akanji OO, Salter DM, Bader DL, Lee DA (2008) Dynamic compression influences interleukin1beta-induced nitric oxide and prostaglandin E2 release by articular chondrocytes via alterations in iNOS and COX-2 expression. Biorheology 45: 257-274.

Colthurst DR, Campbell DG, Proud CG (1987) Structure and regulation of eukaryotic initiation factor eIF2. Sequence of the site in the alpha subunit phosphorylated by the haem-controlled repressor and by the doublestranded RNA-activated inhibitor. Eur J Biochem 166: 357-363.

Daher A, Laraki G, Singh M, Melendez-Peña CE, Bannwarth S, Peters AH, Meurs EF, Braun RE, Patel RC, Gatignol A (2009) TRBP control of PACT-induced phosphorylation of protein kinase $\mathrm{R}$ is reversed by stress. Mol Cell Biol 29: 254-265.
De Croos JN, Dhaliwal SS, Grynpas MD, Pilliar RM, Kandel RA (2006) Cyclic compressive mechanical stimulation induces sequential catabolic and anabolic gene changes in chondrocytes resulting in increased extracellular matrix accumulation. Matrix Biol 25: 323-331.

Etherington J, Spector TD (1995) Asymmetrical nodular osteoarthritis in a patient with a hemiparesis. Ann Rheum Dis 54: 936-937.

Fehrenbacher A, Steck E, Rickert M, Roth W, Richter W (2003) Rapid regulation of collagen but not metalloproteinase 1,3,13,14 and tissue inhibitor of metalloproteinase 1, 2, 3 expression in response to mechanical loading of cartilage explants in vitro. Arch Biochem Biophys 410: 39-47.

Fitzgerald JB, Jin M, Grodzinsky AJ (2006) Shear and compression differentially regulate clusters of functionally related temporal transcription patterns in cartilage tissue. J Biol Chem 281: 24095-24103.

Garcia MA, Gil J, Ventoso I, Guerra S, Domingo E, Rivas C, Esteban M (2006) Impact of protein kinase PKR in cell biology: from antiviral to antiproliferative action. Microbiol Mol Biol Rev 70: 1032-1060.

Gilbert SJ, Duance VC, Mason DJ (2002) Tumour necrosis factor alpha up-regulates protein kinase $\mathrm{R}$ (PKR)activating protein (PACT) and increases phosphorylation of PKR and eukaryotic initiation factor $2-\alpha$ in articular chondrocytes. Biochem Soc Trans 30: 886-889.

Gray ML, Pizzanelli AM, Grodzinsky AJ, Lee RC (1988) Mechanical and physiochemical determinants of the chondrocyte biosynthetic response. J Orthop Res 6: 777-792.

Gray ML, Pizzanelli AM, Lee RC, Grodzinsky AJ, Swann DA (1989) Kinetics of the chondrocyte biosynthetic response to compressive load and release. Biochim Biophys Acta 991: 415-425.

Gruber J, Vincent TL, Hermansson M, Bolton M, Wait R, Saklatvala J (2004) Induction of interleukin-1 in articular cartilage by explantation and cutting. Arthritis Rheum 50: 2539-2546.

Hamby JM, Connolly CJ, Schroeder MC, Winters RT, Showalter HD, Panek RL, Major TC, Olsewski B, Ryan MJ, Dahring T, Lu GH, Keiser J, Amar A, Shen C, Kraker AJ, Slintak V, Nelson JM, Fry DW, Bradford L, Hallak H, Doherty AM (1997) Structure-activity relationships for a novel series of pyrido[2,3-d]pyrimidine tyrosine kinase inhibitors. J Med Chem 40: 2296-2303.

Hardie DG (2007) AMP-activated/SNF1 protein kinases: conserved guardians of cellular energy. Nat Rev Mol Cell Biol 8: 774-785.

Hermansson M, Sawaji Y, Bolton M, Alexander S, Wallace A, Begum S, Wait R, Saklatvala J (2004) Proteomic analysis of articular cartilage shows increased type II collagen synthesis in osteoarthritis and expression of inhibin $\beta A$ (activin A), a regulatory molecule for chondrocytes. J Biol Chem 15: 43514-43521.

Ikenoue T, Trindade MC, Lee MS, Lin EY, Schurman DJ, Goodman SB, Smith RL (2003) Mechanoregulation of human articular chondrocyte aggrecan and type II collagen expression by intermittent hydrostatic pressure in vitro. $\mathrm{J}$ Orthop Res 21: 110-116. 
Jammi NV, Whitby LR, Beal PA (2003) Small molecule inhibitors of the RNA-dependent protein kinase. Biochem Biophys Res Commun 308: 50-57.

Jin G, Sah RL, Li YS, Lotz M, Shyy JY, Chien S (2000) Biomechanical regulation of matrix metalloproteinase-9 in cultured chondrocytes. J Orthop Res 18: 899-908.

Kim YJ, Sah RL, Grodzinsky AJ, Plaas AH, Sandy JD (1994) Mechanical regulation of cartilage biosynthetic behavior: physical stimuli. Arch Biochem Biophys 311: $1-12$.

Korver TH, van de Stadt RJ, Kiljan E, van Kampen GP, van der Korst JK (1992) Effects of loading on the synthesis of proteoglycans in different layers of anatomically intact articular cartilage in vitro. J Rheumatol 19: 905-912.

Larsson T, Aspden RM, Heinegård D (1991) Effects of mechanical load on cartilage matrix biosynthesis in vitro. Matrix 11: 388-94.

Lee CR, Grodzinsky AJ, Spector M (2003) Biosynthetic response of passaged chondrocytes in a type II collagen scaffold to mechanical compression. J Biomed Mater Res A 64: 560-569.

Lee HS, Millward-Sadler SJ, Wright MO, Nuki G, Salter DM (2000) Integrin and mechanosensitive ion channel-dependent tyrosine phosphorylation of focal adhesion proteins and beta-catenin in human articular chondrocytes after mechanical stimulation. J Bone Miner Res 15: 1501-1509.

Lee HS, Millward-Sadler SJ, Wright MO, Nuki G, Al-Jamal R, Salter DM (2002) Activation of integrinRACK1/PKC $\alpha$ signalling in human articular chondrocyte mechanotransduction. Osteoarthritis Cartilage 10: 890897.

Lohmander LS, Englund PM, Dahl LL, Roos EM (2007) The long-term consequence of anterior cruciate ligament and meniscus injuries: osteoarthritis. Am J Sports Med 35: 1756-1769.

Millward-Sadler SJ, Wright MO, Lee H, Nishida K, Caldwell H, Nuki G, Salter DM (1999) Integrinregulated secretion of interleukin 4: A novel pathway of mechanotransduction in human articular chondrocytes. J Cell Biol 145: 183-189.

Montine KS, Henshaw EC (1989) Serum growth factors cause rapid stimulation of protein synthesis and dephosphorylation of eIF-2 in serum deprived Ehrlich cells. Biochim Biophys Acta 1014: 282-288.

Nanduri S, Rahman F, Williams BR, Qin J (2000). A dynamically tuned double-stranded RNA binding mechanism for the activation of antiviral kinase PKR. EMBO J 19: 5567-5574.

Neu CP, Khalafi A, Komvopoulos K, Schmid TM, Reddi AH (2007) Mechanotransduction of bovine articular cartilage superficial zone protein by transforming growth factor beta signaling. Arthritis Rheum 56: 3706-3714.

Palmoski MJ, Brandt KD (1984) Effects of static and cyclic compressive loading on articular cartilage plugs in vitro. Arthritis Rheum 27: 675-681.

Parkkinen JJ, Ikonen J, Lammi MJ, Laakkonen J, Tammi M, Helminen HJ (1993) Effects of cyclic hydrostatic pressure on proteoglycan synthesis in cultured chondrocytes and articular cartilage explants. Arch Biochem Biophys 300: 458-465.

Parkkinen JJ, Lammi MJ, Helminen HJ, Tammi M (1992) Local stimulation of proteoglycan synthesis in articular cartilage explants by dynamic compression in vitro. J Orthop Res 10: 610-620.

Patel CV, Handy I, Goldsmith T, Patel RC (2000) PACT, a stress-modulated cellular activator of interferon-induced double-stranded RNA-activated protein kinase, PKR. J Biol_Chem 275: 37993-37998.

Proud CG (2007) Signalling to translation: how signal transduction pathways control the protein synthetic machinery. Biochem J 403: 217-234.

Roberts SR, Knight MM, Lee DA, Bader DL (2001) Mechanical compression influences intracellular $\mathrm{Ca}^{2+}$ signaling in chondrocytes seeded in agarose constructs. J Appl Physiol 90: 1385-1391.

Sah RL, Kim YJ, Doong JY, Grodzinsky AJ, Plaas AH, Sandy JD (1989) Biosynthetic response of cartilage explants to dynamic compression. J Orthop Res 7: 619-636. Sauerland K, Raiss RX, Steinmeyer J (2003) Proteoglycan metabolism and viability of articular cartilage explants as modulated by the frequency of intermittent loading. Osteoarthritis Cartilage 11: 343-350.

Sen GC, Peters GA (2007) Viral stress-inducible genes. Adv Virus Res 70: 233-263.

Smith RL, Lin J, Trindade MC, Shida J, Kajiyama G, Vu T, Hoffman AR, van der Meulen MC, Goodman SB, Schurman DJ, Carter DR (2000) Time-dependent effects of intermittent hydrostatic pressure on articular chondrocyte type II collagen and aggrecan mRNA expression. J Rehabil Res Dev 37: 153-161.

Stecher RM, Karnosh LJ (1947) Heberden's nodes; the effect of nerve injury upon the formation of degenerative joint disease of the fingers. Am J Med Sci 213: 181-191.

Steinmeyer J, Knue S (1997) The proteoglycan metabolism of mature bovine articular cartilage explants superimposed to continuously applied cyclic mechanical loading. Biochem Biophys Res Commun 240: 216-221.

Tam CL, Hofbauer M, Towle CA (2007) Requirement for protein kinase $\mathrm{R}$ in interleukin-1 $\alpha$-stimulated effects in cartilage. Biochem Pharmacol 74: 1636-1641.

Valhmu WB, Raia FJ (2002) Myo-inositol 1,4,5-trisphosphate and $\mathrm{Ca}^{2+} /$ calmodulin-dependent factors mediate transduction of compression-induced signals in bovine articular chondrocytes. Biochem J 361: 689-696.

Valhmu WB, Stazzone EJ, Bachrach NM, SaedNejad F, Fischer SG, Mow VC, Ratcliffe A (1998) Loadcontrolled compression of articular cartilage induces a transient stimulation of aggrecan gene expression. Arch Biochem Biophys 353: 29-36.

Van Kampen GP, Korver GH, van de Stadt RJ (1994) Modulation of proteoglycan composition in cultured anatomically intact joint cartilage by cyclic loads of various magnitudes. Int J Tissue React 16: 171-179.

Vanwanseele B, Eckstein F, Knecht H, Stüssi E, Spaepen A (2002) Knee cartilage of spinal cord-injured patients displays progressive thinning in the absence of normal joint loading and movement. Arthritis Rheum 46: 2073-2078. 
Vincent T, Hermansson M, Bolton M, Wait R, Saklatvala J (2002) Basic FGF mediates an immediate response of articular cartilage to mechanical injury. Proc Natl Acad Sci USA 99: 8259-8264.

Vincent TL, Hermansson MA, Hansen UN, Amis AA, Saklatvala J (2004) Basic fibroblast growth factor mediates transduction of mechanical signals when articular cartilage is loaded. Arthritis Rheum 50: 526-533.

Vincent TL, McLean CJ, Full LE, Peston D, Saklatvala J. (2007) FGF-2 is bound to perlecan in the pericellular matrix of articular cartilage, where it acts as a chondrocyte mechanotransducer. Osteoarthritis Cartilage 15: 752-763.

Wang X, Proud CG (2008) A novel mechanism for the control of translation initiation by amino acids, mediated by phosphorylation of eukaryotic initiation factor $2 \mathrm{~B}$. Mol Cell_Biol 28: 1429-1442.

Williams BR (2001) Signal integration via PKR. Sci STKE 2001: re2.
Wong M, Siegrist M, Cao X (1999) Cyclic compression of articular cartilage explants is associated with progressive consolidation and altered expression pattern of extracellular matrix proteins. Matrix Biol 18: 391-399.

Wu QQ, Chen Q (2000) Mechanoregulation of chondrocyte proliferation, maturation, and hypertrophy: ion-channel dependent transduction of matrix deformation signals. Exp Cell Res 256: 383-391.

$\mathrm{Xu}$ Z, Williams BR (2000) The B56 $\alpha$ regulatory subunit of protein phosphatase $2 \mathrm{~A}$ is a target for regulation by double-stranded RNA-dependent protein kinase PKR. Mol Cell Biol 20: 5285-5299.

Editor's Note: All questions/comments by the reviewers were answered by text changes. There is hence no "Discussion with Reviewers" section. 